\title{
Endogenous BDNF in the Dorsolateral Striatum Gates Alcohol Drinking
}

\author{
Jerome Jeanblanc, ${ }^{1}$ Dao-Yao He, ${ }^{1}$ Sebastien Carnicella, ${ }^{1}$ Viktor Kharazia, ${ }^{1}$ Patricia H. Janak, ${ }^{1,2,3,4 *}$ and Dorit Ron ${ }^{1,2,3,4 *}$ \\ ${ }^{1}$ Ernest Gallo Research Center, ${ }^{2}$ Neuroscience Graduate Program, ${ }^{3}$ Department of Neurology, and ${ }^{4}$ The Wheeler Center for the Neurobiology of Addiction, \\ University of California, San Francisco, Emeryville, California 94608
}

\begin{abstract}
We previously found that brain-derived neurotrophic factor (BDNF)-haplodeficient mice exhibit greater ethanol-induced place preference and psychomotor sensitization, and greater ethanol consumption after deprivation, than control mice. We further observed that, in mice, voluntary ethanol intake increases BDNF expression in the dorsal striatum (DS). Here, we determined whether BDNF within the DS regulates ethanol self-administration in Long-Evans rats trained to self-administer a $10 \%$ ethanol solution. We observed a greater increase in BDNF expression after ethanol self-administration in the dorsolateral striatum (DLS) than in the dorsomedial striatum (DMS). We further found that downregulation of endogenous BDNF using viral-mediated siRNA in the DLS, but not in the DMS, significantly increased ethanol self-administration. Infusion of exogenous BDNF $(0.25 \mu \mathrm{g} / \mu \mathrm{l} /$ side into the DMS; $0.25 \mathrm{and} 0.75 \mu \mathrm{g} / \mu \mathrm{l} / \mathrm{side}$ into the DLS) attenuated responding for ethanol when infused $3 \mathrm{~h}$ before the beginning of the self-administration session. Although the decrease in ethanol intake was similar in the DLS and DMS, BDNF infused in the DLS, but not in the DMS, induced an early termination of the drinking episode. Furthermore, the action of BDNF in the DLS was specific for ethanol, as infusion of the neurotrophic factor in the DMS, but not DLS, resulted in a reduction of sucrose intake. Together, these findings demonstrate that the BDNF pathway within the DLS controls the level of ethanol self-administration. Importantly, our results suggest that an endogenous signaling pathway within the same brain region that mediates drug-taking behavior also plays a critical role in gating the level of ethanol intake.
\end{abstract}

\section{Introduction}

BDNF belongs to the nerve growth factor (NGF) family of neurotrophic factors (Huang and Reichardt, 2001; Chao, 2003). $\mathrm{BDNF}$ and its receptor TrkB are widely distributed throughout the brain (Wetmore et al., 1990; Altar et al., 1994), and the BDNF/ TrkB pathway plays an important role in neuronal proliferation, differentiation and survival, as well as synaptic plasticity (Chao, 2003). More recently, BDNF has been implicated in psychiatric disorders such as depression and anxiety (Martinowich et al., 2007). In addition, a growing body of literature suggests a role for BDNF in drug addiction (Russo et al., 2009).

Human studies have linked BDNF to alcohol addiction. For example, the region of chromosome 11 containing the BDNF gene has been implicated as a susceptibility locus for addiction to multiple drugs of abuse, including alcohol (Uhl et al., 2001), and a single nucleotide polymorphism in the BDNF gene has been linked with an earlier onset of alcoholism (Matsushita et al., 2004). We and others generated evidence that suggests a role for BDNF in regulating behavioral responses to alcohol (ethanol) in rodents.

\footnotetext{
Received May 12, 2009; revised Sept. 21, 2009; accepted Sept. 22, 2009.

This work was supported by National Institutes of Health-National Institute on Alcohol Abuse and Alcoholism Grant R01 AA016848 (D.R.), the State of California for Medical Research on Alcohol and Substance Abuse through the University of California, San Francisco (D.R. and P.H.J.), and the Wheeler Center for the Neurobiology Addiction (J.J.). We thank Dr. Marian Logrip for her technical and editorial contributions.

*P.H.J. and D.R. contributed equally to this work.

Correspondence should be addressed to Dr. Dorit Ron, 5858 Horton Street, Suite 200, Emeryville, CA 94608.

E-mail: dorit.ron@ucsf.edu.

DOI:10.1523/JNEUROSCI.2243-09.2009

Copyright $\odot 2009$ Society for Neuroscience 0270-6474/09/2913494-09\$15.00/0
}

Specifically, a reduction in BDNF expression in BDNF heterozygous mice (Hensler et al., 2003; McGough et al., 2004) or inhibition of the BDNF receptor TrkB (Jeanblanc et al., 2006) increases ethanol consumption and preference. Moreover, we observed that both acute systemic administration of ethanol and voluntary ethanol intake increase BDNF expression in the DS of mice (McGough et al., 2004; Logrip et al., 2009). We further showed that this increase in BDNF level triggers the expression of downstream effectors, including the dopamine $\mathrm{D}_{3}$ receptor $\left(\mathrm{D}_{3} \mathrm{R}\right)$ and preprodynorphin (Jeanblanc et al., 2006; Logrip et al., 2008), and that inhibition of the $\mathrm{D}_{3} \mathrm{R}$ (Jeanblanc et al., 2006) or of the dynorphin receptor, the $\kappa$ opioid receptor (Logrip et al., 2008), blocks the BDNF-mediated decrease in ethanol consumption. Together, these studies suggest that BDNF may act as an endogenous negative regulator of ethanol intake. However, the localization of this regulatory effect remains unknown.

As mentioned above, we found that ethanol treatment increases BDNF expression specifically in the DS (McGough et al., 2004). The DS has been implicated in the control of goal-directed behaviors and in the formation of habit (White, 1996; Yin and Knowlton, 2006). Specifically, the DMS has been shown to play a role in response-outcome learning (Yin et al., 2005), whereas the DLS is suggested to regulate stimulus-response, or habit learning (White and McDonald, 2002; Featherstone and McDonald, 2004; Yin et al., 2004). In addition, the lateral and medial parts of the DS have distinct anatomical inputs and outputs (Voorn et al., 2004). We were therefore interested in determining whether and where BDNF within the subregions of DS controls the level of ethanol self-administration. 


\section{Materials and Methods}

Animals. Male Long-Evans rats (400-450 g at the time of surgery) were obtained from Harlan. Animals used in the studies were individually housed under a light:dark cycle of $12 \mathrm{~h}$, with lights on at 7:00 A.M. and food and water available ad libitum. All animal procedures in this report were approved by the Gallo Center Institutional Animal Care and Use Committee and were conducted in agreement with the Guide for the Care and Use of Laboratory Animals (National Research Council, 1996). Three to seven animals per group were used for the reverse transcription (RT)PCR and Western blot analysis, and five to twelve animals per group for the behavioral experiments, as indicated in the figure legends.

Reagents. Human BDNF was purchased from Sigma-Aldrich. pRNATH1.1/Shuttle was purchased from GenScript. The adenoviral vector Adeno-X and the Adeno-X Virus Purification Kit were purchased from Clontech. Lipofectamine 2000 and TRIzol were purchased from Invitrogen. PCR master mix $(2 \times)$ and the Reverse Transcription System were purchased from Promega. Anti-GFP antibodies were purchased from Abcam, anti-NeuN antibodies from Millipore. Anti-GFAP and antiactin antibodies were from Sigma-Aldrich, and anti-BDNF polyclonal antibodies (sc-546) were purchased from Santa Cruz Biotechnologies. Secondary antibodies were obtained as follows: donkey anti-rabbit Alexa-Fluor 488 and Alexa Fluor-594-labeled donkey anti-mouse from Invitrogen and donkey anti-mouse $\mathrm{Cy} 3$ conjugate from Jackson ImmunoResearch.

Cloning and preparation of BDNF siRNA recombinant adenovirus. Two 19 nt BDNF siRNA sequences (Baker-Herman et al., 2004), GCTGAGCGTGTGTGACAGT (siBDNF-1) and GAGCTGCTGGATGAGGACC (siBDNF-2), targeting the coding domain of the BDNF mRNA were used for vector-based small-hairpin RNA (shRNA) expression. Two complementary oligonucleotides were synthesized as follows: $5^{\prime}$ GATCCC (19 nt, sense) TTGATATCCG (19 nt, antisense), and TTTTTT CCAAA-3' and 3'-GG (19 nt antisense) AACTATAGGC (19 nt, sense) AAAAAA GGTTTTCGA-5', flanked by BamHI and HindIII residues. The paired oligonucleotides were annealed and ligated into BamHI/HindIII sites of pRNAT-H1.1/Shuttle, a GFP-containing adenoviral shuttle siRNA vector. The pRNAT-siRNA recombinants sequences were confirmed before subcloning into the cloning sites of I-CeuI and PI-SceI of the adenoviral vector Adeno-X. A nonrelated $19 \mathrm{nt}$ sequence (siCT) ATGAACGTGAATTGCTCAA (Ptasznik et al., 2004), was cloned into Adeno-X vector as described above. Preparation of adenoviruses was initiated by transfection of recombinant adenoviral constructs into HEK293 cells using Lipofectamine 2000 according to the Adeno-X Expression System 1 User Manual. Viruses were amplified in HEK293 cells, followed by purification using Adeno-X Virus Purification Kit. Viruses were titered based on GFP-visualized infection. Viruses containing BDNF siRNA or the control sequence were used to infect SH-SY5Y neuroblastoma cells at a multiplicity of infection of $20\left(10^{10} \mathrm{TU} / \mathrm{ml}\right)$.

Cell culture. SH-SY5Y human neuroblastoma cells were cultured in DMEM containing 10\% fetal bovine serum (FBS) and $1 \times$ MEM nonessential amino acid solution (NEAA, Invitrogen). Cells were incubated in DMEM containing $1 \%$ FBS and $1 \times$ NEAA and treated with $10 \mu \mathrm{M}$ retinoic acid for differentiation. Cells were then infected with adenoviruses expressing siBDNF-1, siBDNF-2, or siCT for $3 \mathrm{~d}$ before analysis of $B D N F$ mRNA level.

Brain sample collection for RT-PCR and Western blot analyses. Brains were collected, and slices were cut between $+1.70 \mathrm{~mm}$ and $+0.5 \mathrm{~mm}$ anterior to bregma. The cortex and the ventral striatum were removed ( $-6.00 \mathrm{~mm}$ below the brain surface). The DS was then divided into the DLS and the DMS at $+2.5 \mathrm{~mm}$ from the middle line.

$R T-P C R$. Total RNAs were isolated using Trizol reagent and reverse transcribed using a Reverse Transcription System kit (Promega) at $42^{\circ} \mathrm{C}$ for $30 \mathrm{~min}$. $B D N F, N G F$, and NT3 expression were analyzed by PCR with temperature cycling parameters consisting of initial denaturation at $94^{\circ} \mathrm{C}$ for $2 \mathrm{~min}$ followed by 32 cycles of denaturation at $94^{\circ} \mathrm{C}$ for $30 \mathrm{~s}$, annealing at $58^{\circ} \mathrm{C}$ for $30 \mathrm{~s}$, extension at $72^{\circ} \mathrm{C}$ for $1 \mathrm{~min}$, and a final incubation at $72^{\circ} \mathrm{C}$ for $7 \mathrm{~min}$. PCR for the control genes, glyceraldehyde-3-phosphate dehydrogenase $(G A P D H)$ and actin, was run with the same temperature cycling parameters for 30 cycles. The following primers were used: rat
BDNF, upstream 5' -TTG AGC ACG TGA TCG AAG AGC-3' and downstream $5^{\prime}$-GTT CGG CAT TGC GAG TTC CAG-3'; rat NGF, upstream 5'-ACA CTC TGG ATC TAG ACT TCC AGG-3' and downstream $5^{\prime}{ }^{\prime}-$ AGG CAA GTC AGC CTC TTC TTG TAG-3'; rat NT3, upstream 5'CTA CTA CGG CAA CAG AGA CGC TAC- $3^{\prime}$ and downstream $5^{\prime}$-TGT CAA TGG CTG AGG ACT TGT CGG-3'; rat GAPDH, upstream 5' -TGA AGG TCG GTG TGA ACG GAT TTG GC-3' and downstream 5'-CAT GTA GGC CAT GAG GTC CAC CAC-3'; human BDNF, upstream 5' CTT TGG TTG CAT GAA GGC TGC-3' and downstream $5^{\prime}-\mathrm{G}$ TCT ATC CTT ATG AAT CGC CAG-3'; human actin, upstream 5' -TCA TGA AGT GTG ACG TTG ACA TC-3' and downstream 5' -AGA AGC ATT TGC GGT GGA CGA TG-3'. PCR products were separated on $1.8 \%$ agarose gel in Tris/acetic acid/EDTA buffer with $0.25 \mu \mathrm{g} / \mathrm{ml}$ ethidium bromide and photographed by Eagle Eye II (Stratagene). The images were scanned and the signals of the PCR products were quantified by densitometry using the NIH Image 1.61 program. The intensities of signal of BDNF, NGF, and NT3 were normalized to GAPDH or actin as indicated in the figure legends.

Western blot analysis. The DLS and DMS were dissected and homogenized in radio-immunoprecipitation assay (RIPA) buffer $(50 \mathrm{~mm}$ Tris$\mathrm{HCl}, \mathrm{pH}$ 7.6, $150 \mathrm{~mm} \mathrm{NaCl}, 1 \%$ Nonidet P-40, 0.1\% SDS, 0.5\% sodium deoxycholate, 2 mM EDTA, protease inhibitor cocktail) at $4^{\circ} \mathrm{C}$ using the homogenizer TH115 PowerGen 125 (Fisher Scientific) for $10 \mathrm{~s}$. The homogenates ( $40 \mu \mathrm{g}$ of protein each) were resolved on a $16 \%$ SDS-PAGE gel at constant voltage of $180 \mathrm{~V}$ and transferred to a nitrocellulose membrane (Millipore), and blocked in a milk solution (5\% milk in TBS-T: 20 mм Tris-HCl, pH 7.6, $137 \mathrm{~mm} \mathrm{NaCl}$, and 0.1\% Tween 20). Membranes were incubated with polyclonal anti-BDNF antibodies diluted (1:1000) in a milk solution overnight at $4^{\circ} \mathrm{C}$. Membranes were then washed 3 times with TBS-T, followed by incubation with anti-rabbit horseradish peroxidase (HRP)-conjugated secondary antibodies diluted (1:1000) in a milk solution for $1 \mathrm{~h}$ at room temperature and washes were repeated 3 times. Immunoreactivity was detected by using enhanced chemiluminescence (ECL) detection kit (GE Healthcare) and processed by exposure to Kodak BioMax film. The film was developed using SRX-101A Medical Film Processor (Konica Minolta). The membrane was stripped in a stripping buffer (100 mm 2-mercapto-ethanol, $62.5 \mathrm{~mm}$ Tris-HCl, 2\% SDS, $\mathrm{pH}$ 6.7) at $50^{\circ} \mathrm{C}$ for $30 \mathrm{~min}$, washed three times in TBS-T, and reprobed with anti-actin antibodies, which was used as an internal control. The images were scanned and the immunoreactivity signal of proteins were quantified by densitometry using the NIH Image 1.61 program. The intensity of the immunoreactivity of BDNF was normalized to actin.

Immunohistochemistry. Rats were deeply anesthetized with Euthasol (Virbac), and intracardially perfused with $0.9 \% \mathrm{NaCl}$ for $2 \mathrm{~min}$, followed by cold $4 \%$ paraformaldehyde (PFA) in phosphate buffer (PB), pH 7.4, for $10 \mathrm{~min}$. Brains were removed, fixed in $4 \%$ PFA for $2 \mathrm{~h}$ at $4^{\circ} \mathrm{C}$, and transferred to $\mathrm{PB}$ at $4^{\circ} \mathrm{C}$. The following day, brains were transferred into $30 \%$ sucrose in PBS until fully sunk. Coronal sections $(50 \mu \mathrm{m})$ were cut using a cryostat Leica CM3050 (Leica Instruments), collected in PB, and stored at $4^{\circ} \mathrm{C}$. Free-floating sections were first permeabilized with $50 \%$ ethanol for $20 \mathrm{~min}$, rinsed in PBS, then blocked with $10 \%$ normal donkey serum in PBS for $30 \mathrm{~min}$, and incubated for $48 \mathrm{~h}$ at $4^{\circ} \mathrm{C}$ on an orbital shaker with antibodies for either neuronal marker (monoclonal antiNeuN, 1:100) or glial marker (monoclonal anti-GFAP; 1:1000) in combination with the polyclonal rabbit anti-GFP antibody (ab290, 1:10,000), diluted in PBS $/ 0.05 \%$ Triton X-100. Sections were then washed three times for 5 min with PBS, and then incubated with $2 \%$ normal donkey serum for $10 \mathrm{~min}$ and incubated in a mixture of secondary antibodies: Alexa Fluor-594-labeled donkey anti-mouse or donkey anti-mouse Cy3 conjugate (to detect either NeuN or GFAP) and Alexa Fluor-488-labeled donkey anti-rabbit (to detect GFP) for $3 \mathrm{~h}$. After staining, sections were washed in PBS, mounted on gelatin-subbed slides, briefly air dried, and coverslipped using Vectashield mounting medium with DAPI (Vector Laboratories). Images were acquired using LSM 510 META laser confocal microscope with multichannel excitation and detection options using optimal factory recommended filter configurations to minimize spectral bleed-through (Zeiss). The colocalization of markers and spread of infection were analyzed using MetaMorph 6.3 software (Molecular Devices) and SigmaScan Pro 5.0 (Systat Software). 
Ethanol operant self-administration. Following 3 weeks of exposure to ethanol in the home cage, rats were trained to self-administer a solution of $10 \%$ ethanol $(\mathrm{v} / \mathrm{v})$. The self-administration chambers contain two levers: an active lever (the ethanol lever) for which presses resulted in delivery of a $0.1 \mathrm{ml}$ of fluid reward (a 10\% ethanol solution), and an inactive lever, for which presses were counted but no programmed events occurred. After $3 \mathrm{~d}$ under a fixed ratio 1 (FR1, one press delivers one reward) schedule, the rats were trained on an FR3 schedule (three presses are required to receive one reward) for $60 \mathrm{~min}$ sessions either $5 \mathrm{~d} /$ week (BDNF infusion experiments) or $7 \mathrm{~d} /$ week (BDNF mRNA knockdown experiments). Animals were trained for at least 5 weeks before the beginning of the experimental manipulations; this length of training results in ethanol intakes in a range of 0.3 to $0.7 \mathrm{~g} / \mathrm{kg}$ in $1 \mathrm{~h}$ leading to a blood ethanol concentration from 5 to $25 \mathrm{mg} \%$ (supplemental Fig. 1, available at www.jneurosci.org as supplemental material). During the selfadministration sessions, several parameters (number of presses on the levers, number of ethanol deliveries, latency to the first press, latency to the first reward, delay between presses, latency to the last press) were recorded using MED-PC IV software (Med Associates).

BDNF $m R N A$ level measurements after ethanol self-administration. Rats trained to self-administer ethanol for at least 5 weeks as described above were placed into the operant conditioning chambers for a 30 min session of ethanol self-administration. Thirty minutes after the end of the session (i.e., $1 \mathrm{~h}$ after the beginning of the ethanol self-administration session), rats were killed, and the DLS and DMS were dissected out and processed for RT-PCR as described above.

Determination of blood ethanol concentration. Tail blood was collected in heparinized capillary tubes from rats immediately at the end of a 60 min ethanol self-administration session. Serum was extracted with $3.4 \%$ trichloroacetic acid followed by a 5 min centrifugation at $420 \mathrm{~g}$, and assayed for ethanol content using the nicotinamide adenine dinucleotide (NAD-NADH) enzyme spectrophotometric method (Zapata et al., 2006). Blood ethanol concentration was determined by using a standard calibration curve.

Sucrose operant self-administration. Rats were initially trained in 2 overnight sessions under an FR1 schedule using $0.1 \mathrm{ml}$ of an $8 \%$ sucrose solution as the reinforcer. Subsequently, rats were trained $5 \mathrm{~d}$ a week in 60 min sessions, with the FR schedule progressively increased to FR3 and the sucrose concentration progressively decreased to $2 \%$.

Microinfusion of virus into the DLS and DMS. Stereotaxic injections of the viruses were conducted once the rats had reached a stable baseline of ethanol self-administration for at least 7 consecutive days. Rats were continuously anesthetized with isoflurane (Baxter) during the surgery. Two holes were drilled above the sites of injection to allow the introduction of the injectors (Acute Internal Cannula, C315IA, 33 ga, Plastics One). The injectors were connected to Hamilton syringes ( $25 \mu \mathrm{l} \# 1702$ ), and infusion was controlled by an automatic pump (Harvard Apparatus). As the size of the targeted structures is not uniform, rats received three injections of $1 \mu \mathrm{l}$ of solution per side in the DLS and two injections of $1 \mu \mathrm{l}$ per side for the DMS at a rate of $0.5 \mu \mathrm{l} / \mathrm{min}$, and the injectors remained in place for 10 additional minutes. The coordinates used for the injections into the DLS were as follows: injection \#1: $+1.2 \mathrm{~mm}$ anterior to bregma, $\pm 3.5 \mathrm{~mm}$ lateral to the medial suture, and $-4.5 \mathrm{~mm}$ ventral to the skull surface; injection $\# 2:+0.2 \mathrm{~mm}$ anterior to bregma, $\pm 3.5 \mathrm{~mm}$ lateral to the medial suture, and $-5.5 \mathrm{~mm}$ ventral to the skull surface; injection \#3: $+0.2 \mathrm{~mm}$ anterior to bregma, $\pm 3.5 \mathrm{~mm}$ lateral to the medial suture, and $-4.5 \mathrm{~mm}$ ventral to the skull surface. The coordinates used for the injections into the DMS were as follows: injection \#1: $+1.2 \mathrm{~mm}$ anterior to bregma, $\pm 1.5 \mathrm{~mm}$ lateral to the medial suture, and $-4.5 \mathrm{~mm}$ ventral to the skull surface; injection \#2: $+0.2 \mathrm{~mm}$ anterior to bregma, $\pm 1.5 \mathrm{~mm}$ lateral to the medial suture, and $-4.5 \mathrm{~mm}$ ventral to the skull surface. After $1 \mathrm{~d}$ of recovery, the subjects were returned to selfadministration training until the end of the experiment.

Cannula implantation into the DLS, DMS, and shell of the nucleus accumbens. Rats were continuously anesthetized with isoflurane (Baxter) during the surgery. Four holes were drilled for screws, and two other holes were drilled for the placement of the cannulae (DLS: single cannula C315GA; DMS: double cannulae C235G, $3 \mathrm{~mm}$ between the cannulae;
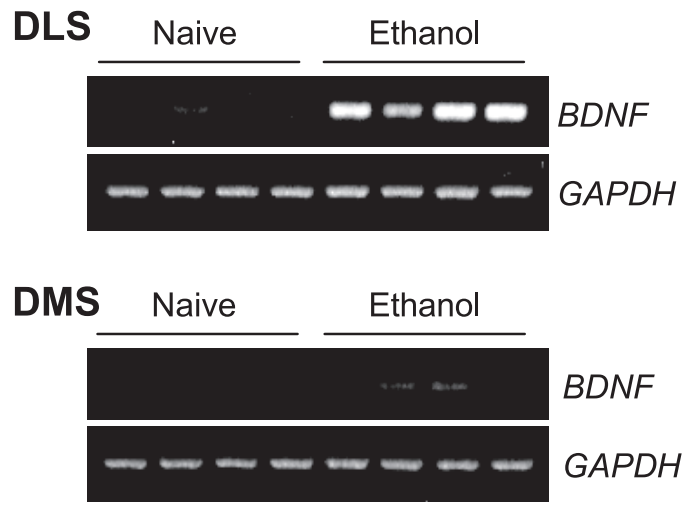

Figure 1. Ethanol self-administration differentially upregulates BDNF expression within the DLS and the DMS. Rats were killed 30 min after the end of a 30 min self-administration session, and brain samples were collected for RT-PCR analysis and compared with naive animals $(n=4)$. To avoid inaccuracy of the analysis due to the low baseline levels of BDNF expression in the naive groups, quantification was not conducted.

shell of the NAc: double cannulae C235G, 2 mm between the cannulae; $26 \mathrm{ga}$, Plastics One). The coordinates for the DLS were $+1.2 \mathrm{~mm}$ anterior to bregma and $\pm 3.5 \mathrm{~mm}$ lateral to the medial suture. The cannulae were implanted into the lateral part of the dorsal striatum $(-4.2 \mathrm{~mm}$ from the skull surface) and fixed with dental cement. The coordinates for the DMS were $+1.0 \mathrm{~mm}$ anterior to bregma, $\pm 1.5 \mathrm{~mm}$ lateral to the medial suture, and $-4.2 \mathrm{~mm}$ from the skull surface. The coordinates for the shell of the nucleus accumbens (NAc) were $+1.4 \mathrm{~mm}$ anterior to bregma, $\pm 1 \mathrm{~mm}$ lateral to the medial suture, and $-6.8 \mathrm{~mm}$ from the skull surface. Subject weights were monitored daily after the surgery to ensure a healthy recovery of each rat. One week after recovery, subjects returned to selfadministration training and were habituated to the microinjection procedure with two sham injections. The experimental microinjections began upon acquisition of a stable level of responding. The injectors used for each group extended $0.5 \mathrm{~mm}$ below the tip of the cannula.

Microinfusion of BDNF into the DLS, DMS, and shell of the NAc. BDNF doses were chosen according to Lu et al. which showed that 0.25 or 0.75 $\mu \mathrm{g} / \mu \mathrm{l}$ BDNF microinfused into the VTA are sufficient to alter cocaine seeking (Lu et al., 2004). BDNF or PBS was infused via a $25 \mu \mathrm{l}$ Hamilton syringe (\#1702) $3 \mathrm{~h}$ before the beginning of the self-administration session. BDNF $(0.75 \mu \mathrm{g} / \mu \mathrm{l})$ was also infused into the DLS $10 \mathrm{~min}$ before the beginning of the session. For the DMS and DLS injections, the volume infused was $1 \mu \mathrm{l}$ and the infusion lasted $2 \mathrm{~min}$; due to the small size of the shell of the NAc, and to limit the possible diffusion of BDNF to the DMS, a volume of $0.5 \mu$ l was microinfused into the shell of the NAc over $2.5 \mathrm{~min}$. The injectors remained in position for an additional $2 \mathrm{~min}$. Rats were returned to the home cage until the beginning of the self-administration session. The order of injections was counterbalanced across all subjects for each brain region.

Histology. Rats implanted with cannulae were perfused transcardially with the fixative (4\% PFA), then $75 \mu \mathrm{m}$ coronal slices were cut and examined for cannula placements. The placements of cannulae are shown in supplemental Figure 2 (available at www.jneurosci.org as supplemental material). Animals in which the cannula placements were not in the appropriate brain area were removed from the study. Specifically, 2 rats were removed from the experiment in which BDNF was infused into the DLS and 1 rat was excluded from the group in which BDNF was infused into the shell of the NAc.

Data analysis. Biochemical and behavioral data were analyzed by oneor two-way ANOVA with repeated measures, depending on the experiment, followed by the Student-Newman-Keuls test when indicated by significant effects of treatments or interactions. For simple comparisons, data were analyzed by a Student's $t$ test. Significance for all tests was set at $p<0.05$. 
a

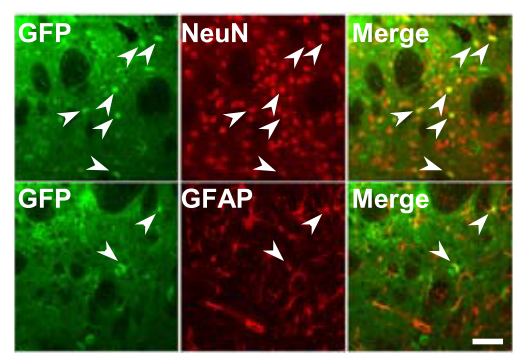

C

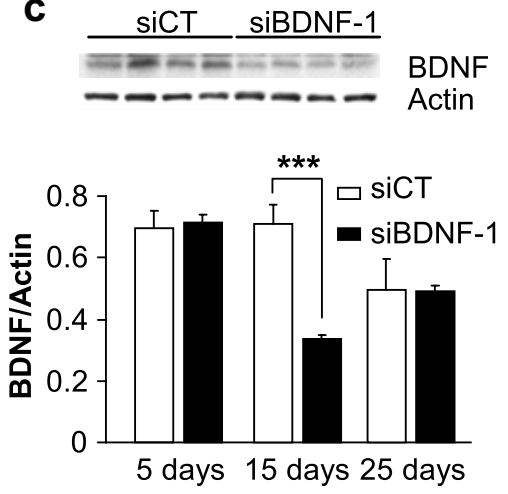

e

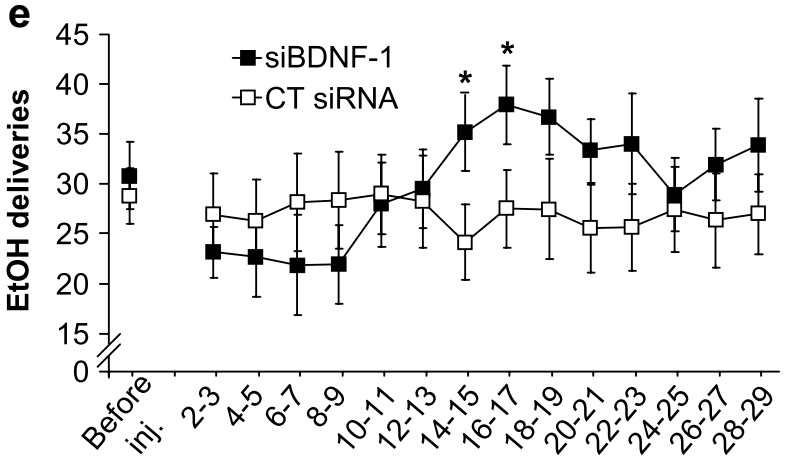

Figure 2. Knockdown of BDNF expression within the DLS increases ethanol self-administration. $\boldsymbol{a}$, Rats were stereotaxically infused with siBDNF-1 $\left(10^{10} \mathrm{TU} / \mathrm{ml}\right)$ into the DLS. Fifteen days after the microinjection, striatal slices were prepared and stained for virus-expressed GFP (green) along with either NeuN (top panel, red), or GFAP (bottom panel, red). The scale bar represents 100 $\mu \mathrm{m} . \boldsymbol{b}$, siBDNF-1 or siCT were stereotaxically injected into the DLS of rats. Five, 15 , and $25 \mathrm{~d}$ after the microinjection, DLS were collected for RT-PCR analysis. siBDNF-1 time-dependently decreased BDNF expression in the DLS. Histograms depict the mean ratios of $B D N F / G A P D H \pm$ SEM normalized to $B D N F$ levels obtained from control animals. The insert is a representative image of BDNFmRNA levels from samples collected 15 d after infection by the siCT- or siBDNF-1-expressing virus. $(n=7),{ }^{*} p<0.05,{ }^{* *} p<$ 0.01. c, Rats were treated as described in $\boldsymbol{b}$ and brain samples were collected, 5, 15, or $25 \mathrm{~d}$ after injection, and analyzed by Western blot to determine BDNF protein levels. The samples from the three different time points were separated on three different gels to ensure comparison between siBDNF-1 and siCT injections within each time points. The insert is a representative image of BDNF protein levels from samples collected $15 \mathrm{~d}$ after infection by the siCT- or siBDNF-1-expressing virus. $(n=3-4),{ }^{* * *} p<0.001$. d, $\boldsymbol{e}$, Rats were stereotaxically infused with siBDNF-1 or siCT $\left(10^{10} \mathrm{TU} / \mathrm{ml}\right)$ into the DLS 2 months after the beginning of ethanol self-administration training. $\boldsymbol{d}$, Injection of siBDNF-1 increases ethanol self-administration 15-16 d after infusion. Results are expressed as mean \pm SEM ethanol consumed in grams per kilogram. siBDNF-1: $n=12$; siCT: $n=11 ;{ }^{*} p<0.05$. $\boldsymbol{e}$, BDNF knockdown in the DLS increases the number of ethanol deliveries. The results are expressed as mean \pm SEM ethanol deliveries by blocks of 2 d. siBDNF-1: $n=12$; siCT: $n=11 ;{ }^{*} p<0.05$.

\section{Results}

Ethanol self-administration differentially increases BDNF mRNA levels within the DLS and the DMS

We previously showed that both ethanol consumption and systemic injection of $2 \mathrm{~g} / \mathrm{kg}$ ethanol leads to an increase in BDNF expression in the DS in mice (McGough et al., 2004). Therefore, we tested whether an increase in $B D N F$ mRNA expression can be detected within the DLS and/or the DMS of rats after ethanol self-administration. The average number of ethanol deliveries for this group of rats during a 30 min session was $23.5 \pm 6.65$, which corresponds to a mean estimated concentration of $0.34 \pm 0.097 \mathrm{~g} / \mathrm{kg}$. Interestingly, we found that ethanol self-administration induced a dramatic increase in BDNF expression within the DLS but only a small increase within the DMS (Fig. 1).

\section{BDNF knockdown in the DLS increases} ethanol self-administration

To study the possible role of endogenous BDNF in the DLS in the regulation of ethanol self-administration, we used the adenovirus-mediated delivery of siRNA (Davidson and Breakefield, 2003) to knock down the level of the neurotrophic factor. Two distinct BDNF siRNA sequences (Baker-Herman et al., 2004), were cloned into an adenoviral shuttle vector containing green fluorescent protein (GFP), which was recombined into an adenoviral vector. BDNF siRNA recombinant adenoviruses (siBDNF-1 and siBDNF-2) significantly reduced the expression level of $B D N F$ in SH-SY5Y neuroblastoma cells compared with uninfected cells and cells infected with a control nonspecific RNA sequence-recombinant adenovirus ( (supplemental Fig. 3, available at www. jneurosci.org as supplemental material). Next, we injected siBDNF-1 into the DLS of rats and monitored the level of viral infection. As shown in Figure $2 a$, a high level of virus infection was detected in DLS neurons as measured by costaining of GFP with the neuronal marker NeuN, while a lower level of infection was detected in glia as measured by costaining of GFP with the glial marker GFAP. The infection spread was within a radius of $\sim 500 \mu \mathrm{m}$ from the infusion needle track (supplemental Fig. $4 a$, available at www. jneurosci.org as supplemental material), indicating that it is unlikely that the infection extended laterally from the DLS to the DMS. Next, we measured the level of $B D N F$ mRNA in the DLS after the administration of siBDNF-1, and observed a decrease in BDNF expression $5 \mathrm{~d}$ after infusion of siBDNF-1, which was still observed $15 \mathrm{~d}$, but not $25 \mathrm{~d}$, later (Fig. $2 b$ ). A two-way ANOVA revealed a significant effect of treatment $\left(F_{(1,35)}=5.2, p<0.05\right)$ and an interaction between treatment and time points $\left(F_{(2,35)}=4.8, p<0.05\right)$. Furthermore, the downregulation of $B D N F$ mRNA levels was specific, since infection of 
the DLS did not result in a decrease in the mRNA levels of the related neurotrophic genes, $N G F$ (supplemental Fig. $4 b$, available at www.jneurosci.org as supplemental material) and neurotrophin-3 (NT3) (supplemental Fig. $4 c$, available at www.jneurosci. org as supplemental material). We also tested the level of the BDNF protein in the DLS after infection with siBDNF-1 and found a reduction $15 \mathrm{~d}$ after virus infusion (Fig. 2c). A Student's $t$ test revealed a significant difference between the siBDNF-1 group and the siCT group for the time point of $15 \mathrm{~d}$ after infusion $(p<0.001)$. Although the anti-BDNF antibodies recognize both the mature form of BDNF and pro-BDNF, we were unable to detect pro-BDNF in our experiments, which is likely to be due to the fast processing of pro-BDNF to the mature form of the protein. The reduction in the expression of the protein was localized to the site of infusion (i.e., the DLS), as the level of BDNF was unaltered in the DMS (supplemental Fig. $4 d$, available at www.jneurosci.org as supplemental material). We also analyzed the levels of the internal controls used for the mRNA (i.e., GAPDH) and for the protein (i.e., actin) to ensure that the levels of these controls were not altered after infection with siBDNF-1. As shown in supplemental Figure 4, $e$ and $f$ (available at www. jneurosci.org as supplemental material), the densities of the bands of GAPDH and actin are not modified by siBDNF-1 infection compared with siCT $(p>0.05)$. Together, these results show that adenovirus-mediated BDNF siRNAs decrease BDNF expression, which corresponds with a decrease in BDNF protein level.

Operant self-administration of ethanol was used next to test the behavioral consequences of BDNF knockdown in the DLS. Rats were trained on a fixed-ratio 3 schedule to lever press for delivery of $0.1 \mathrm{ml}$ aliquots of a $10 \%$ ethanol solution in daily $1 \mathrm{~h}$ sessions. Lever-press responding and estimated ethanol consumption in grams per kilogram of body weight were measured before, during, and after infusion of siBDNF-1 or siCT. Because we found significant decreases in BDNF mRNA and protein $15 \mathrm{~d}$ after viral infusion, we tested whether ethanol self-administration would be altered at this time point. We found that BDNF knockdown in the DLS significantly increased ethanol self-administration 15-16 d after viral infusion $(p<0.05)$ (Fig. $2 d$ ). When ethanol self-administration was examined across the 29 sessions after viral infusion, we observed a progressive increase in the number of ethanol deliveries beginning 8-9 d after infusion of the siBDNF-1 virus, and reaching a maximum at $16-17 \mathrm{~d}$ after infusion (Fig. $2 e$ ); the number of deliveries then gradually returned to baseline levels $24-25 \mathrm{~d}$ after virus infusion. A Student's t test did not reveal any differences in the number of ethanol deliveries between the two groups before the infusion. A two-way repeated-measures ANOVA on the time course of the behavior after viral infusion found a main effect of time $\left(F_{(13,221)}=2.5, p<0.01\right)$, no main effect of virus treatment $\left(F_{(1,221)}=0.3, \mathrm{~ns}\right)$, and a significant interaction between treatment and time $\left(F_{(13,221)}=3.6, p<0.001\right)$. The post hoc analysis revealed a significant difference between the
siBDNF-1 and siCT groups for the time points $14-15$ and $16-17$ $\mathrm{d}$ after infusion.

Thus, both BDNF levels and ethanol deliveries returned to baseline 25-26 d after the injection (Fig. 2c,e). These results were further confirmed by the use of the siBDNF-2, which produced a comparable decrease in BDNF mRNA levels (supplemental Fig. $5 a$, available at www.jneurosci.org as supplemental material) and a similar increase in ethanol consumption (supplemental Fig. 5b, available at www.jneurosci.org as supplemental material) $15 \mathrm{~d}$ after infusion of the virus.

Analysis of the interethanol delivery interval (IEDIs) distribution (a measure of the time between each successive ethanol reinforcer delivery) for day 15 after infusion for both treatment groups found no main effect of treatment $\left(F_{(1,120)}=2.6\right.$; ns $)$, and no interaction between treatment and time $\left(F_{(20,120)}=1.031 ; \mathrm{ns}\right)$ (supplemental Fig. 6, available at www.jneurosci.org as supplemental material). In addition, the mean latency to the first reward did not differ significantly between the two treatment groups $\left(F_{(1,21)}=0.0012 ; \mathrm{ns}\right)$ (supplemental Table 1, available at www. jneurosci.org as supplemental material). Together, these results demonstrate that reduction in BDNF levels within the DLS significantly increases ethanol operant self-administration without changing the initiation of the drinking episode.

\section{Downregulation of BDNF in the DMS does not alter ethanol self-administration}

Next, we tested the contribution of endogenous BDNF in the DMS to the regulation of ethanol self-administration. Although infusion of the siBDNF-1 significantly decreased BDNF expression (Fig. $3 a$ ) and BDNF protein levels (Fig. $3 b$ ) within the DMS, 

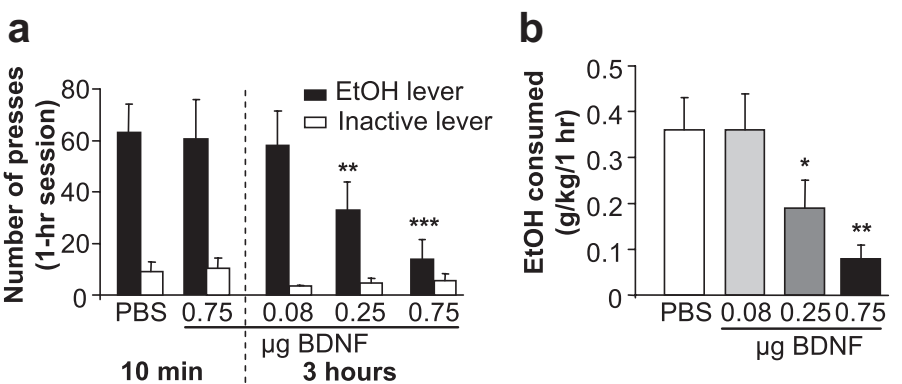

C

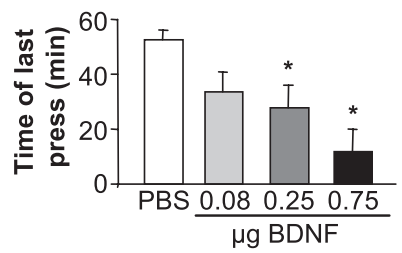

d

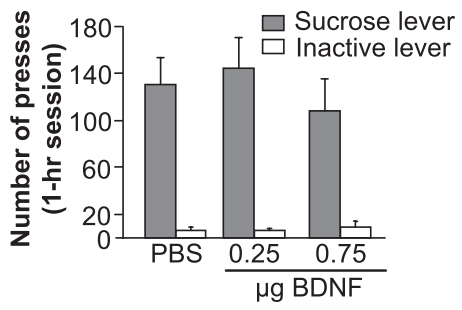

Figure 4. BDNF injection into the DLS decreases ethanol self-administration by inducing an early termination of the drinking episode. Rats were microinjected with PBS or BDNF into the DLS $10 \mathrm{~min}(0.75 \mu \mathrm{g} / \mu \mathrm{l} / \mathrm{side}$ over $2 \mathrm{~min})$ or $3 \mathrm{~h}(0.08,0.25$, and $0.75 \mu \mathrm{g} / \mu \mathrm{l} / \mathrm{side}$ over $2 \mathrm{~min}$ ) before the beginning of the self-administration session. $\boldsymbol{a}$, BDNF injected into the DLS dose-dependently decreases ethanol selfadministration only when injected $3 \mathrm{~h}$ before the beginning of the session. Data are expressed as mean \pm SEM number of presses. $n=8$; ${ }^{* *} p<0.01,{ }^{* * *} p<0.001$ versus PBS group. $\boldsymbol{b}$, Data are presented as mean \pm SEM ethanol consumed in grams per kilogram. $n=8$; ${ }^{*} p<0.05,{ }^{* *} p<0.01$.c, BDNF induces an early termination of the drinking episode. Results are expressed as the mean \pm SEM time of the last press in minutes. PBS and BDNF $0.08 \mu \mathrm{g} / \mu \mathrm{l}: n=8 ; \mathrm{BDNF} 0.25 \mu \mathrm{g} / \mu \mathrm{l}: n=7 ; \mathrm{BDNF} 0.75 \mu \mathrm{g} / \mu \mathrm{l}: n=4 ;{ }^{*} p<0.05 . d$, BDNFinjection into the DLS does not alter sucrose self-administration. BDNF was injected into the DLS $3 \mathrm{~h}$ before the session of rats trained to selfadminister sucrose for at least 2 months. The data are represented as mean \pm SEM number of presses. $n=12$.
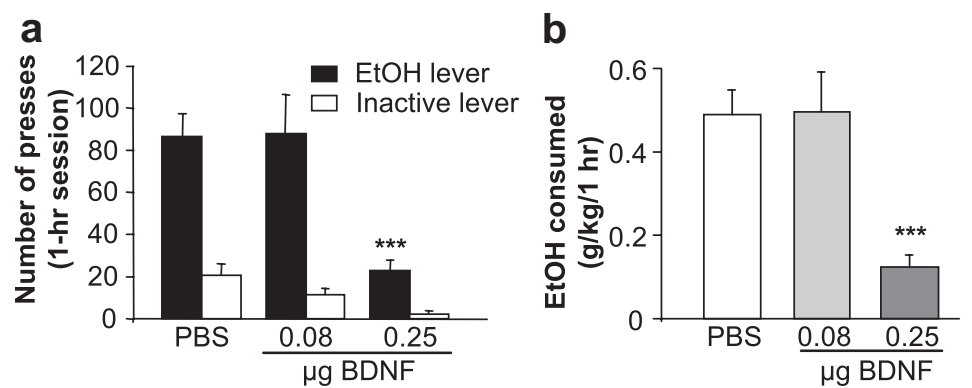

C
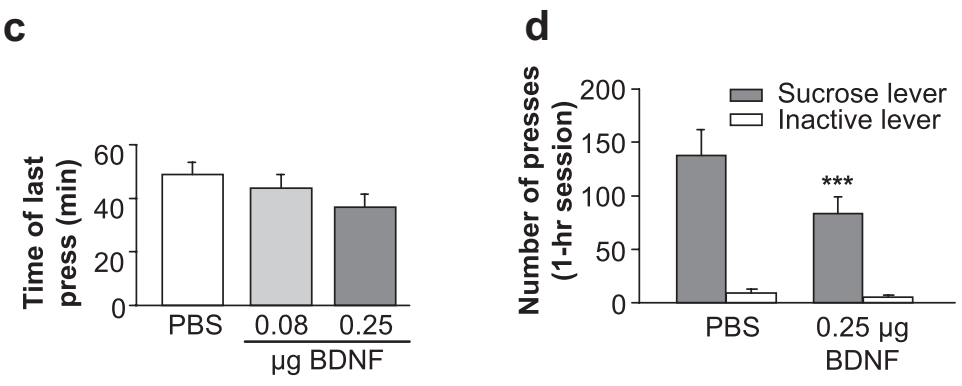

Figure 5. BDNF injection into the DMS decreases ethanol and sucrose self-administration. Rats were microinjected with PBS or BDNF ( 0.08 and $0.25 \mu \mathrm{g} / \mu \mathrm{l} /$ side) into the DMS $3 \mathrm{~h}$ before the beginning of the self-administration session. $\boldsymbol{a}$, BDNF infused into the DMS decreased the number of presses on the ethanol lever. Data are expressed as mean \pm SEM number of presses. $n=10$; ${ }^{* * *} p<0.001$. $\boldsymbol{b}$, BDNF injected into the DMS decreases ethanol consumption. $n=10$; ${ }^{* * *} p<0.001$. $\boldsymbol{c}$, BDNF injected into the DMS does not induce an early termination of the drinking episode. Results are expressed as mean $\pm S E M$ time of the last press in minutes. $n=11$. $\boldsymbol{d}$, BDNF microinjected into the DMS decreases sucrose self-administration. $n=7 ;{ }^{* * *} p<0.001$.

we did not observe a change in ethanol self-administration 15-16 $\mathrm{d}$ after infusion (Fig. $3 c$ ). Moreover, BDNF mRNA knockdown within the DMS did not have any effect on the number of ethanol deliveries (Fig. 3d). No difference was observed between the siBDNF-1 group and the siCT group before the infusion of the virus (Student's $t$ test, $p>0.05$ ) and a two-way repeated- measures ANOVA on the behavioral time course found no effect of treatment $\left(F_{(1,100)}=1.0, \mathrm{~ns}\right)$, time $\left(F_{(10,100)}=0.9\right.$, $\mathrm{ns})$, nor an interaction between these factors $\left(F_{(10,100)}=1.3\right.$, ns $)$. These findings suggest that the actions of endogenous BDNF to control the level of ethanol selfadministration are localized to the DLS.

\section{Infusion of BDNF into the DLS}

decreases ethanol self-administration

If the site of action of BDNF to regulate ethanol consumption is indeed the DLS, then activation of the BDNF pathway within this region should result in the opposite effect, i.e., the reduction of responding for ethanol. To test this possibility, the BDNF polypeptide was infused directly into the DLS, and ethanol operant self-administration was monitored. We found that BDNF administration dosedependently decreased ethanol operant self-administration when injected $3 \mathrm{~h}$, but not $10 \mathrm{~min}$, before the beginning of the session, and no significant effects were observed on inactive lever responding (Fig. 4a). A two-way repeated-measures ANOVA revealed significant main effects of lever $\left(F_{(1,28)}=28.9 ; p<0.001\right)$ and treatment $\left(F_{(4,28)}=7.7 ; p<0.001\right)$, as well as an interaction between both factors $\left(F_{(4,28)}=\right.$ 7.9; $p<0.001)$. This decrease in ethanol presses led to a decrease in ethanol deliveries as shown in supplemental Figure $7 a$ (available at www.jneurosci.org as supplemental material). As a consequence of the reduction of the number of ethanol deliveries, consumption of ethanol during the self-administration session was significantly decreased by BDNF (Fig. 4b), as indicated by a significant main effect of treatment $\left(F_{(3,18)}=9.5, p<0.001\right)$ on mean concentration in grams per kilogram.

Although the total number of responses was decreased after infusion of BDNF into the DLS, this treatment did not alter the distribution of IEDIs during the session. After the injection of $0.75 \mu \mathrm{g} / \mu \mathrm{l} \mathrm{BDNF}$, only two rats pressed at least six times, the minimum required to receive two rewards and thus to measure an IEDI. Hence, the IEDI analysis was conducted on the results for 0.08 and $0.25 \mu \mathrm{g} / \mu \mathrm{l}$ BDNF and vehicle. We found that the distribution of the IEDIs was unchanged (supplemental Fig. $7 b$, available at www.jneurosci.org as supplemental material). Next, we analyzed the latency to the first reward for rats meeting the minimum requirement for at least three responses (i.e., one reward delivery). As shown in supplemental Table 2 (available at www. jneurosci.org as supplemental material), BDNF did not alter the latency to the first reward. On the contrary, BDNF induced a premature termination of responding confirmed by the analysis 
of the time at which the final lever-press response of the session occurred. As shown in Figure $4 c$, the time of the last press occurred significantly earlier after treatment with the two highest doses of BDNF $(0.25$ and $0.75 \mu \mathrm{g} / \mu \mathrm{l} /$ side $)$ compared with PBS. A one-way repeated-measures ANOVA on the time of the last press found a main effect of treatment $\left(F_{(3,15)}=3.9, p<0.05\right)$. The post hoc analysis revealed significant differences between the PBS treatment and both the 0.25 and $0.75 \mu \mathrm{g} / \mu \mathrm{l} /$ side BDNF injections $(p<$ 0.05 for both comparisons).

Finally, to ensure that the attenuation of ethanol self-administration was specific, we tested the effect of heat-inactivated BDNF on ethanol self-administration. As shown in supplemental Figure 8 (available at www.jneurosci.org as supplemental material), infusion of the denatured protein into the DLS did not alter responding for ethanol. Together, these results strongly suggest that the DLS is the site of BDNF's action to regulate ethanol self-administration.

\section{Intra-DLS infusion of BDNF does not alter sucrose self-administration}

Next, we tested whether the alteration of ethanol operant selfadministration by BDNF is due to a reduction of the reinforcing effects of rewarding substances in general. BDNF was therefore infused into the DLS, and operant responding for the natural reward sucrose was measured. We found that microinjection of BDNF into this brain region did not alter sucrose self-administration (Fig. $4 d$ ), suggesting that BDNF's actions are specific for ethanol and are not due to a general attenuation of responding for reward. A two-way repeated-measures ANOVA found no effect of treatment $\left(F_{(2,22)}=1.2, \mathrm{~ns}\right)$ and no interaction between treatment and lever $\left(F_{(2,22)}=2.2 ; \mathrm{ns}\right)$.

\section{Infusion of BDNF into the DMS decreases ethanol and sucrose self-administration}

Next, we tested whether the BDNF signaling pathway in the DMS also plays a role in the regulation of ethanol consumption. We found that administration of the neurotrophic factor significantly decreased the number of presses on the ethanol lever (Fig. $5 a)$ [main effect of treatment $\left(F_{(2,18)}=21.01, p<0.001\right)$, main effect of lever $\left(F_{(2,18)}=27.9, p<0.001\right)$, treatment $\times$ lever interaction $\left.\left(F_{(2,18)}=9.3, p=0.002\right)\right]$, and the number of ethanol deliveries (supplemental Fig. 9a, available at www.jneurosci.org as supplemental material), as well as the quantities of consumed ethanol (Fig. 5b) [main effect of treatment $\left(F_{(2,18)}=16.4, p<\right.$ $0.001)]$. The post hoc analyses revealed a significant difference between PBS and $0.25 \mu \mathrm{g} / \mu \mathrm{l} /$ side of BDNF for both number of responses and for concentration in grams per kilogram $(p<$ 0.001 for both comparisons). However, BDNF injected in the DMS did not alter the pattern of drinking since it had no effect on either the latency to the first reward (supplemental Table 3, available at www.jneurosci.org as supplemental material) or the distribution of IEDIs (supplemental Fig. 9b, available at www. jneurosci.org as supplemental material). Interestingly, the decrease in overall responding for ethanol was not associated with a decrease in the latency to the last press of the session (Fig. $5 c$ ) [no effect of treatment $\left.\left(F_{(2,19)}=1.5, \mathrm{~ns}\right)\right]$, suggesting that the rats continued to press for ethanol during the entire session. To test whether the effect of BDNF in the DMS is specific to ethanol, the neurotrophic factor was infused into this brain region of rats trained to self-administer sucrose $3 \mathrm{~h}$ before the beginning of the session. We found that infusion of BDNF into the DMS significantly decreased the number of presses on the sucrose lever (Fig. $5 d$ ). A two-way repeated-measures ANOVA revealed main effects
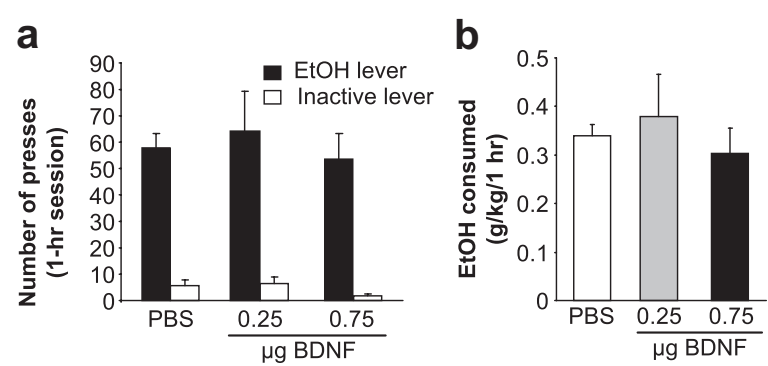

Figure 6. BDNF injection into the shell of the NAC does not alter ethanol selfadministration. Rats were microinjected with PBS or BDNF $(0.25 \mu \mathrm{g} / \mu \mathrm{l} /$ side and 0.75 $\mu \mathrm{g} / \mu \mathrm{l} / \mathrm{side}$ ) into the shell of the NAc $3 \mathrm{~h}$ before the beginning of the operant ethanol selfadministration session. Number of lever presses $(\boldsymbol{a})$ and ethanol consumption $(\boldsymbol{b})$ were similar between the two groups. $n=5$.

of treatment $\left(F_{(1,6)}=11.2, p<0.05\right)$ and of lever $\left(F_{(1,6)}=35.2\right.$, $p=0.001)$, and an interaction between treatment and lever $\left(F_{(1,6)}=\right.$ $10.7, p<0.05)$. The post hoc analysis revealed a significant difference in presses on the active lever between the two treatments $(p<0.001)$. These results suggest that the activation of the BDNF pathway in the DMS results in a general reduction in responding for reward.

\section{Infusion of BDNF in the shell of the NAc does not alter ethanol self-administration}

Finally, we tested the specificity of BDNF's actions on ethanol self-administration in the DS by infusion of BDNF into the shell of the NAc. As a primary component of the brain's reward circuitry (Hyman et al., 2006), the NAc (ventral striatum) in general, and the shell of the NAc in particular, play a crucial role in ethanol reinforcement (Gonzales et al., 2004). However, we observed no change in the number of presses on the ethanol lever (treatment: $F_{(1,4)}=0.1, \mathrm{~ns}$; treatment $\times$ lever interaction: $F_{(1,4)}=$ $0.9, \mathrm{~ns}$ ) after the infusion of the neurotrophic factor (Fig. $6 a$ ), no change in the number of ethanol deliveries (supplemental Fig. 10, available at www.jneurosci.org as supplemental material), and thus no change in the amount of ethanol consumed (treatment: $F_{(2,8)}=0.5$, ns) (Fig. $6 b$ ). These results suggest a specific role for BDNF in the DS and, in particular, in the lateral part of the DS, to control the level of ethanol self-administration.

\section{Discussion}

Endogenous BDNF in the DLS plays a critical role in gating the level of ethanol self-administration

Here we show that the expression level of $B D N F$ is increased in rats administering ethanol in an operant self-administration paradigm. These results are in line with our previous findings in mice consuming ethanol in a two-bottle choice paradigm (McGough et al., 2004; Logrip et al., 2009). Therefore, although the basal level of BDNF in the striatum is relatively lower than in other brain regions it can be clearly detected in the DS and is altered in response to ethanol. Interestingly, the ethanol consumptionmediated induction of $B D N F$ expression is much greater in the DLS than in the DMS. These results correspond with the findings that knockdown of BDNF within the DLS, but not in the DMS, resulted in an increase in ethanol self-administration. Therefore, using RNAi, we were not only able to decrease the basal level of the BDNF expression in the DLS, but additionally we blocked the endogenous homeostatic BDNF system that normally is upregulated in response to ethanol. 


\section{Differential time-dependent decrease in BDNF mRNA and BDNF protein levels}

The decrease in BDNF mRNA was detected earlier than the protein, at $5 \mathrm{~d}$ after injection of the siBDNF. As BDNF protein levels are much more stable than the RNA levels (Nawa et al., 1995), and since BDNF can be recycled (Santi et al., 2006) and thus reused, the delay between the decrease in BDNF mRNA and $\mathrm{BDNF}$ protein is likely due to the time required to process and downregulate the pool of the polypeptide. BDNF can be produced by glial cells (Riley et al., 2004), and therefore we cannot rule out that BDNF in astrocytes contributes to the protective actions of the neurotrophic factor. However, this possibility is unlikely since BDNF expression in the brain is detected mainly in neurons but not in astrocytes (Ernfors et al., 1990; Hofer et al., 1990; Maisonpierre et al., 1990; Wetmore et al., 1990), and only minor infection by the adenovirus was detected in astrocytes.

\section{Exogenous BDNF injected into the DLS shortens ethanol-drinking episodes}

Interestingly, infusion of exogenous BDNF into both subregions of the DS resulted in the attenuation of ethanol self-administration. However, the actions of BDNF in the DLS and DMS are clearly different. Application of BDNF in the DLS, but not the DMS, decreases the time of the final lever press response resulting in early termination, whereas this measure did not change after BDNF infusion into the DMS. In addition, after BDNF infusion into the DLS, only 2 rats out of 8 pressed enough to get two rewards, whereas 10 out of 11 rats pressed for ethanol after infusion of the neurotrophic factor into the DMS. Thus, the early termination of responding and the low number of rats pressing for ethanol after BDNF infusion into the DLS is consistent with a possible decrease in the reinforcing effects of ethanol rather than a satiety effect. Furthermore, the inhibition of ethanol selfadministration by BDNF in the DLS is specific to ethanol, whereas exogenous BDNF in the DMS also affects responding for a natural reward, i.e., sucrose. Therefore, BDNF in the DMS might have a general effect on instrumental responding for reward or on the motivation for reward in general, whereas our results suggest that BDNF in the DLS has a specific role in ethanol reinforcement.

The functional differences described to the two DS subregions in the control of instrumental responding is particularly intriguing: the DLS portion controls responding supported by stimulusresponse associations (White and McDonald, 2002; Featherstone and McDonald, 2004; Yin et al., 2004), whereas the DMS controls responding supported by response-outcome associations (Yin et al., 2005). These studies, in conjunction with the demonstration of distinct anatomical inputs and outputs to and from the lateral and medial parts of the DS (Voorn et al., 2004; Belin et al., 2009), have led to the possibility that the DLS mediates habit/stimulusresponse learning and memory processes that may underlie addictive phenotypes such as compulsive drug and ethanol administration (Everitt and Robbins, 2005). Interestingly, ethanol self-administration has been described to be a habitual rather than a goal-directed behavior (Dickinson et al., 2002). Thus, our results suggest that the action of endogenous BDNF on ethanol self-administration takes place in the same brain region most strongly implicated in habit learning, i.e., the DLS. Because BDNF appears to control termination rather than initiation of responding for ethanol, we suggest that the reinforcing properties of ethanol that may normally serve to support maintenance of the stimulus-response association underlying lever pressing for ethanol, are negatively regulated by BDNF.

\section{Delayed effect of exogenous BDNF on ethanol self-administration}

The regulation of responding for ethanol by BDNF only occurs when BDNF is injected $3 \mathrm{~h}$, but not $10 \mathrm{~min}$, before the beginning of the session. This delay between the injection and the effect of BDNF suggests that the actions of the neurotrophic factor are mediated by a transcription/translation event. This possibility is further supported by our previous studies suggesting that BDNFmediated increases in the $\mathrm{D}_{3} \mathrm{R}$ and dynorphin in the striatum are required for the reduction in ethanol consumption (Jeanblanc et al., 2006; Logrip et al., 2008). It is however, plausible that other proteins could be of equal importance in controlling the level of ethanol consumption via BDNF in the DLS, an area of investigation that we are actively pursuing.

\section{Differential role of striatal BDNF in ethanol- and cocaine-related behaviors}

BDNF may dampen various phenotypes associated with exposure to ethanol and stimulants via actions within specific brain regions. Pandey et al. reported that the reduction in BDNF levels in the central and medial nuclei of the amygdala resulted in increased anxiety and higher ethanol consumption in rats (Pandey et al., 2006). Pandey et al. further showed that the anxiogenic effects of ethanol withdrawal were linked to decreases in the expression of BDNF, and that infusion of BDNF in the central nucleus of the amygdala reversed ethanol withdrawal-induced anxiety (Pandey et al., 2008). In addition, Berglind et al. (2007) showed that a single microinjection of BDNF into the medial prefrontal cortex immediately following the final cocaine selfadministration session attenuated cocaine seeking $22 \mathrm{~h}$ after the infusion. A recent study by the same group found that the single injection of BDNF into the prefrontal cortex normalized cocaineinduced increases in glutamatergic neurotransmission in the NAc (Berglind et al., 2009). However, several lines of evidence indicate that BDNF may have opposite effects on cocaine selfadministration and seeking via its actions in the VTA and NAc. Specifically, BDNF protein levels were found to be increased in the NAc, VTA, and amygdala during the "incubation of craving" period following cocaine self-administration (Grimm et al., 2003). In line with these results, Lu et al. (2004) reported that a single infusion of BDNF into the VTA increased cocaine seeking, and Graham et al. (2007) showed that multiple injections of BDNF into the NAc shell increased cocaine self-administration, cocaine seeking, and reinstatement. The strikingly different role that BDNF appears to play in mechanisms that underlie or attenuate self-administration of cocaine and ethanol is intriguing, and might reveal very important signaling and/or brain region specificity differences that are valuable for understanding the mechanisms that underlie or protect against addiction to ethanol and cocaine.

\section{Conclusions}

Our data suggest a novel role for BDNF in the DLS in gating ethanol self-administration. Specifically, we propose that endogenous BDNF in the DLS controls the level of ethanol selfadministration by reducing or holding in check the reinforcing effects of ethanol, possibly thereby preventing the escalation to uncontrolled use and abuse of the drug. Therefore, increasing BDNF expression or activation of this pathway may be a new strategy to combat alcohol abuse and alcoholism. 


\section{References}

Altar CA, Siuciak JA, Wright P, Ip NY, Lindsay RM, Wiegand SJ (1994) In situ hybridization of trkB and trkC receptor mRNA in rat forebrain and association with high-affinity binding of [125I]BDNF, [125I]NT-4/5 and [125I]NT-3. Eur J Neurosci 6:1389-1405.

Baker-Herman TL, Fuller DD, Bavis RW, Zabka AG, Golder FJ, Doperalski NJ, Johnson RA, Watters JJ, Mitchell GS (2004) BDNF is necessary and sufficient for spinal respiratory plasticity following intermittent hypoxia. Nat Neurosci 7:48-55.

Belin D, Jonkman S, Dickinson A, Robbins TW, Everitt BJ (2009) Parallel and interactive learning processes within the basal ganglia: Relevance for the understanding of addiction. Behav Brain Res 199:89-102.

Berglind WJ, See RE, Fuchs RA, Ghee SM, Whitfield TW Jr, Miller SW, McGinty JF (2007) A BDNF infusion into the medial prefrontal cortex suppresses cocaine seeking in rats. Eur J Neurosci 26:757-766.

Berglind WJ, Whitfield TW Jr, LaLumiere RT, Kalivas PW, McGinty JP (2009) A single intra-PFC infusion of BDNF prevents cocaine-induced alterations in extracellular glutamate within the nucleus accumbens. J Neurosci 29:3715-3719.

Chao MV (2003) Neurotrophins and their receptors: a convergence point for many signalling pathways. Nat Rev Neurosci 4:299-309.

Davidson BL, Breakefield XO (2003) Viral vectors for gene delivery to the nervous system. Nat Rev Neurosci 4:353-364.

Dickinson A, Wood N, Smith JW (2002) Alcohol seeking by rats: action or habit? Q J Exp Psychol B 55:331-348.

Ernfors P, Wetmore C, Olson L, Persson H (1990) Identification of cells in rat brain and peripheral tissues expressing mRNA for members of the nerve growth factor family. Neuron 5:511-526.

Everitt BJ, Robbins TW (2005) Neural systems of reinforcement for drug addiction: from actions to habits to compulsion. Nat Neurosci 8:14811489.

Featherstone RE, McDonald RJ (2004) Dorsal striatum and stimulusresponse learning: lesions of the dorsolateral, but not dorsomedial, striatum impair acquisition of a stimulus-response-based instrumental discrimination task, while sparing conditioned place preference learning. Neuroscience 124:23-31.

Gonzales RA, Job MO, Doyon WM (2004) The role of mesolimbic dopamine in the development and maintenance of ethanol reinforcement. Pharmacol Ther 103:121-146.

Graham DL, Edwards S, Bachtell RK, DiLeone RJ, Rios M, Self DW (2007) Dynamic BDNF activity in nucleus accumbens with cocaine use increases self-administration and relapse. Nat Neurosci 10:1029-1037.

Grimm JW, Lu L, Hayashi T, Hope BT, Su TP, Shaham Y (2003) Timedependent increases in brain-derived neurotrophic factor protein levels within the mesolimbic dopamine system after withdrawal from cocaine: implications for incubation of cocaine craving. J Neurosci 23:742-747.

Hensler JG, Ladenheim EE, Lyons WE (2003) Ethanol consumption and serotonin-1A (5-HT1A) receptor function in heterozygous BDNF $(+/-)$ mice. J Neurochem 85:1139-1147.

Hofer M, Pagliusi SR, Hohn A, Leibrock J, Barde YA (1990) Regional distribution of brain-derived neurotrophic factor mRNA in the adult mouse brain. EMBO J 9:2459-2464.

Huang EJ, Reichardt LF (2001) Neurotrophins: roles in neuronal development and function. Annu Rev Neurosci 24:677-736.

Hyman SE, Malenka RC, Nestler EJ (2006) Neural mechanisms of addiction: the role of reward-related learning and memory. Annu Rev Neurosci 29:565-598.

Jeanblanc J, He DY, McGough NN, Logrip ML, Phamluong K, Janak PH, Ron D (2006) The dopamine $\mathrm{D}_{3}$ receptor is part of a homeostatic pathway regulating ethanol consumption. J Neurosci 26:1457-1464.

Logrip ML, Janak PH, Ron D (2008) Dynorphin is a downstream effector of striatal BDNF regulation of ethanol intake. FASEB J 22:2393-2404.

Logrip ML, Janak PH, Ron D (2009) Escalating ethanol intake is associated with altered corticostriatal BDNF expression. J Neurochem 109:14591468 .
Lu L, Dempsey J, Liu SY, Bossert JM, Shaham Y (2004) A single infusion of brain-derived neurotrophic factor into the ventral tegmental area induces long-lasting potentiation of cocaine seeking after withdrawal. J Neurosci 24:1604-1611.

Maisonpierre PC, Belluscio L, Friedman B, Alderson RF, Wiegand SJ, Furth ME, Lindsay RM, Yancopoulos GD (1990) NT-3, BDNF, and NGF in the developing rat nervous system: parallel as well as reciprocal patterns of expression. Neuron 5:501-509.

Martinowich K, Manji H, Lu B (2007) New insights into BDNF function in depression and anxiety. Nat Neurosci 10:1089-1093.

Matsushita S, Kimura M, Miyakawa T, Yoshino A, Murayama M, Masaki T, Higuchi S (2004) Association study of brain-derived neurotrophic factor gene polymorphism and alcoholism. Alcohol Clin Exp Res 28:16091612.

McGough NN, He DY, Logrip ML, Jeanblanc J, Phamluong K, Luong K, Kharazia V, Janak PH, Ron D (2004) RACK1 and brain-derived neurotrophic factor: a homeostatic pathway that regulates alcohol addiction. J Neurosci 24:10542-10552.

Nawa H, Carnahan J, Gall C (1995) BDNF protein measured by a novel enzyme immunoassay in normal brain and after seizure: partial disagreement with mRNA levels. Eur J Neurosci 7:1527-1535.

Pandey SC, Zhang H, Roy A, Misra K (2006) Central and medial amygdaloid brain-derived neurotrophic factor signaling plays a critical role in alcohol-drinking and anxiety-like behaviors. J Neurosci 26:8320-8331.

Pandey SC, Zhang H, Ugale R, Prakash A, Xu T, Misra K (2008) Effector immediate-early gene arc in the amygdala plays a critical role in alcoholism. J Neurosci 28:2589-2600.

Ptasznik A, Nakata Y, Kalota A, Emerson SG, Gewirtz AM (2004) Short interfering RNA (siRNA) targeting the Lyn kinase induces apoptosis in primary, and drug-resistant, BCR-ABL1(+) leukemia cells. Nat Med 10:1187-1189.

Riley CP, Cope TC, Buck CR (2004) CNS neurotrophins are biologically active and expressed by multiple cell types. J Mol Histol 35:771-783.

Russo SJ, Mazei-Robison MS, Ables JL, Nestler EJ (2009) Neurotrophic factors and structural plasticity in addiction. Neuropharmacology 56 [Suppl 1]:73-82.

Santi S, Cappello S, Riccio M, Bergami M, Aicardi G, Schenk U, Matteoli M, Canossa M (2006) Hippocampal neurons recycle BDNF for activitydependent secretion and LTP maintenance. EMBO J 25:4372-4380.

Uhl GR, Liu QR, Walther D, Hess J, Naiman D (2001) Polysubstance abusevulnerability genes: genome scans for association, using 1,004 subjects and 1,494 single-nucleotide polymorphisms. Am J Hum Genet 69:12901300 .

Voorn P, Vanderschuren LJ, Groenewegen HJ, Robbins TW, Pennartz CM (2004) Putting a spin on the dorsal-ventral divide of the striatum. Trends Neurosci 27:468-474.

Wetmore C, Ernfors P, Persson H, Olson L (1990) Localization of brainderived neurotrophic factor mRNA to neurons in the brain by in situ hybridization. Exp Neurol 109:141-152.

White NM (1996) Addictive drugs as reinforcers: multiple partial actions on memory systems. Addiction 91:921-949; discussion 951-965.

White NM, McDonald RJ (2002) Multiple parallel memory systems in the brain of the rat. Neurobiol Learn Mem 77:125-184.

Yin HH, Knowlton BJ (2006) The role of the basal ganglia in habit formation. Nat Rev Neurosci 7:464-476.

Yin HH, Knowlton BJ, Balleine BW (2004) Lesions of dorsolateral striatum preserve outcome expectancy but disrupt habit formation in instrumental learning. Eur J Neurosci 19:181-189.

Yin HH, Ostlund SB, Knowlton BJ, Balleine BW (2005) The role of the dorsomedial striatum in instrumental conditioning. Eur J Neurosci 22:513-523.

Zapata A, Gonzales RA, Shippenberg TS (2006) Repeated ethanol intoxication induces behavioral sensitization in the absence of a sensitized accumbens dopamine response in C57BL/6J and DBA/2J mice. Neuropsychopharmacology 31:396-405. 